\title{
Características de carcaça e da carne de suínos machos castrados e imunocastrados alimentados com diferentes níveis nutricionais
}

\author{
Carcass characteristics and meat of surgically castrated and immunocastrated pigs fed different \\ nutritional levels
}

\author{
Eloiza Lanferdini ${ }^{*}$ Paulo Alberto Lovatto ${ }^{\mathrm{I}}{ }^{\dagger}$ Raquel Melchior $^{\mathrm{I}}$ Cristieli Carolina Klein ${ }^{\mathrm{I}}$ \\ Jomara Broch ${ }^{\mathrm{I}}$ Gerson Guarez Garcia ${ }^{\mathrm{I}}$
}

\section{RESUMO}

O trabalho foi realizado para avaliar as características de carcaça e carne de suínos machos castrados $e$ imunocastrados alimentados com dietas contendo diferentes níveis nutricionais. $O$ delineamento experimental foi inteiramente casualizado com quatro tratamentos principais (T1-suínos machos castrados alimentados com dieta basal; T2-machos imunocastrados alimentados com dieta basal; T3machos imunocastrados alimentados com dieta basal+3\% aminoácidos e energia; T4-machos imunocastrados alimentados com dieta basal $+5 \%$ aminoácidos e energia) $e$ dois tratamentos secundários com ou sem ractopamina dentro de cada tratamento principal. Os suínos machos castrados apresentaram peso de abate 3,3\% inferior $(P<0,05)$, peso de carcaça fria $1,4 \%$ superior $(P<0,05)$ e peso de carré $13 \%$ superior $(P<0,05)$ em relação aos machos imunocastrados. Suínos machos imunocastrados suplementados com 5\% a mais de aminoácidos e energia apresentaram costela 19\% mais $(P<0,05)$ pesada e valores superiores $(P<0,05)$ na coloração $b^{*}$ (amarelo-azul) na carne aos $45 \mathrm{~min}$ e às $24 \mathrm{~h}$ pós-abate em relação aos machos castrados alimentados com a dieta basal. A suplementação com $5 \%$ de aminoácidos e energia aumenta $o$ peso e rendimento de costela e altera o valor da coloração $b^{*}$ (amarelo-azul) na carne aos $45 \mathrm{~min}$ e às $24 \mathrm{~h}$ pós-abate de suínos machos imunocastrados.

Palavras-chave: energia, pós-abate, proteína, ractopamina, suinocultura.

\section{ABSTRACT}

The study was carried out to evaluate the carcass characteristics and meat of surgically castrated and immunocastrated pigs fed with different nutritional levels. The animals were distribuited in a completely randomized experimental design with four main treatments (T1-surgically castrated pigs fed with basal diet; T2-immunocastrated pigs fed with basal diet; T3-immunocastrated pigs fed with basal diet $+3 \%$ amino acids and energy; T4-immunocastrated pigs fed with basal diet $+5 \%$ amino acids and energy) and two secondary treatments with or without ractopamine within each main treatment. The surgically castrated pigs had slaughter weight $3.3 \%$ lower $(P<0.05)$, cold carcass weight $1.4 \%$ higher $(P<0.05)$ and loin chop weight $13 \%$ higher $(P<0.05)$ compared to immunocastred pigs. The immunocastrated pigs supplemented with 5\% more amino acids and energy had rib $19 \%$ more heavier $(P<0.05)$ and higher values $(P<0.05)$ in the color $b^{*}$ (yellow-blue) in the meat to $45 \mathrm{~min}$ and $24 \mathrm{~h}$ postslaughter compared with surgically castrated pigs fed with basal diet. Supplementation with 5\% amino acids and energy increases weight and yield of rib and changes the value of color $b^{*}$ (yellow-blue) in the meat to $45 \mathrm{~min}$ and $24 \mathrm{~h}$ postslaughter male pigs immunocastrated.

Key words: energy, post-slaughter, protein, ractopamine, swine production.

\section{INTRODUÇÃO}

A produção de suínos machos inteiros tem se mostrado uma prática bastante atrativa, pois a categoria tem maior potencial fisiológico para deposição proteica e melhor eficiência alimentar (PAULY et al., 2009). Destaca-se, assim, a imunocastração, que consiste na vacinação dos animais com uma forma modificada de GnRH, conjugada a uma proteína que induz a formação de anticorpos anti-GnRH (ZAMARATSKAIA et al., 2008).

IDepartamento de Zootecnia, Universidade Federal de Santa Maria (UFSM), Avenida Roraima, 1000, Bairro Camobi 97105-900,

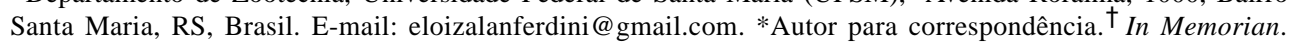


Os fatores que influenciam na eficiência de deposição de proteína nos suínos e, consequentemente, na exigência de lisina dos animais são o genótipo, peso corporal e o sexo. A lisina é o aminoácido mais importante para a deposição de carne magra na carcaça de suínos, porém, a resposta dos animais é afetada pelo balanço ideal dos aminoácidos essenciais e da energia (KIM et al., 2009). Um aditivo que pode aumentar a produção de carne é a ractopamina (DUNSHEA et al., 1993). Agonista ß-adrenérgico do grupo das fenetanolaminas, a ractopamina é uma substância exógena que altera a partição dos nutrientes para deposição muscular e de gordura (ARMSTRONG et al., 2004). Portanto, o ajuste dos aminoácidos e da proteína da dieta às exigências dos animais e a adição de ractopamina pode resultar em carne de melhor qualidade.

No Brasil, a produção de suínos machos imunocastrados foi rapidamente adotada e as estratégias nutricionais e alimentares não acompanharam essa evolução. As exigências de energia, proteína bruta e aminoácidos para diferentes categorias sexuais nem sempre são fornecidas em tabelas de exigências. Portanto, o objetivo deste trabalho foi avaliar o peso e rendimento da carcaça e dos cortes e a qualidade da carne de suínos machos castrados e imunocastrados alimentados com dietas contendo diferentes níveis de aminoácidos e energia com ou sem ractopamina.

\section{MATERIAL E MÉTODOS}

O experimento foi realizado no Setor de Suínos do Departamento de Zootecnia da Universidade Federal de Santa Maria. Foram utilizados 72 suínos, machos castrados e inteiros, homogêneos geneticamente, oriundos de criação comercial, com peso médio inicial de $20 \mathrm{~kg}$ e 63 dias de idade. Os animais foram alojados em baias com $4,5 \mathrm{~m}^{2}$, de piso compacto, equipadas com comedouro e bebedouro automático.

O delineamento experimental foi inteiramente casualizado com quatro tratamentos principais e dois tratamentos secundários, com três repetições cada. Os tratamentos principais foram: T1 - suínos machos castrados alimentados com dieta basal; T2 - suínos machos imunocastrados alimentados com dieta basal; T3 - suínos machos imunocastrados alimentados com dieta basal + 3\% aminoácidos e energia; T4 - suínos machos imunocastrados alimentados com dieta basal + 5\% aminoácidos e energia. Os dois tratamentos secundários foram com ou sem ractopamina dentro de cada tratamento principal. A relação aminoácidos: energia foi mantida em todos os tratamentos. A ractopamina foi adicionada nos últimos 28 dias pré-abate, após a aplicação da segunda dose da vacina de imunocastração.
As dietas comerciais (Tabela 1) foram formuladas a fim de atender às exigências nutricionais dos suínos com alto potencial genético, usados no experimento. Os ingredientes (milho e farelo de soja) e a ração basal foram previamente analisados para determinação de aminoácidos, proteína bruta, energia, matéria seca. Os aminoácidos foram determinados pela técnica que emprega cromatografia líquida de alta performance (HPLC - High-performance liquid chromatography). A ração basal comercial foi comum a todos os tratamentos, equivalente a $90 \%$ da ração total nos tratamentos com aumento nos níveis nutricionais. A fração diferencial de $10 \%$ foi adicionada posteriormente, com a finalidade de aumentar os níveis de aminoácidos, proteína e energia da dieta. A ração foi fornecida à vontade e os animais tiveram livre acesso à água. Os animais receberam as dietas por 103 dias, sendo que, nos últimos 28 dias pré-abate, as dietas eram com ou sem adição de ractopamina.

A primeira dose da vacina de imunocastração foi aplicada quando os suínos machos inteiros atingiram peso médio de $65 \mathrm{~kg}$ e a segunda dose 28 dias antes do abate, sendo $2 \mathrm{~mL}$ por dose, via subcutânea. Os suínos foram abatidos em estabelecimento comercial sob vigilância do Serviço de Inspeção Federal (SIF). Para coleta de dados pósabate, foram selecionados 24 animais (três animais por tratamento), sendo um animal por unidade experimental. Para a escolha do animal foi considerado o indivíduo com peso vivo mais próximo da média observada na unidade experimental.

As variáveis medidas foram: peso de abate, peso e rendimento de carcaça quente e fria (sem cabeça) e de cortes, $\mathrm{pH}$, perda de peso e cor da carne. No coxão mole, foram medidos o $\mathrm{pH}$ aos $45 \mathrm{~min}, 24 \mathrm{e} 48 \mathrm{~h}$; perda de peso às 24 e $48 \mathrm{~h}$ e cor aos $45 \mathrm{~min}$ e $24 \mathrm{~h}$. A cor foi analisada com colorímetro portátil Minolta. Os componentes $\mathrm{L}^{*}$ (luminosidade), $\mathrm{a}^{*}$ (vermelho-verde) e b* (amarelo-azul) foram expressos no sistema de cor CIELAB. Os dados foram submetidos à análise de variância pelo procedimento General Linear Model do programa Minitab 15 (MINITAB, 2007), sendo o peso de abate utilizado como covariável nas variáveis de rendimento. As diferenças entre as médias foram comparadas pelo teste Tukey a 5\% de significância.

\section{RESULTADOS E DISCUSSÃO}

Os suínos machos castrados apresentaram peso de abate $3,3 \%$ inferior $(\mathrm{P}<0,05)$ e peso de carcaça fria $1,4 \%$ superior aos machos imunocastrados, ambos alimentados com a dieta basal (Tabela 2). A ractopamina aumentou $(\mathrm{P}<0,05)$ o peso de abate e de carcaça quente. 
Tabela 1 - Composição centesimal, bromatológica e relação aminoácido/energia e aminoácido/aminoácido das dietas experimentais.

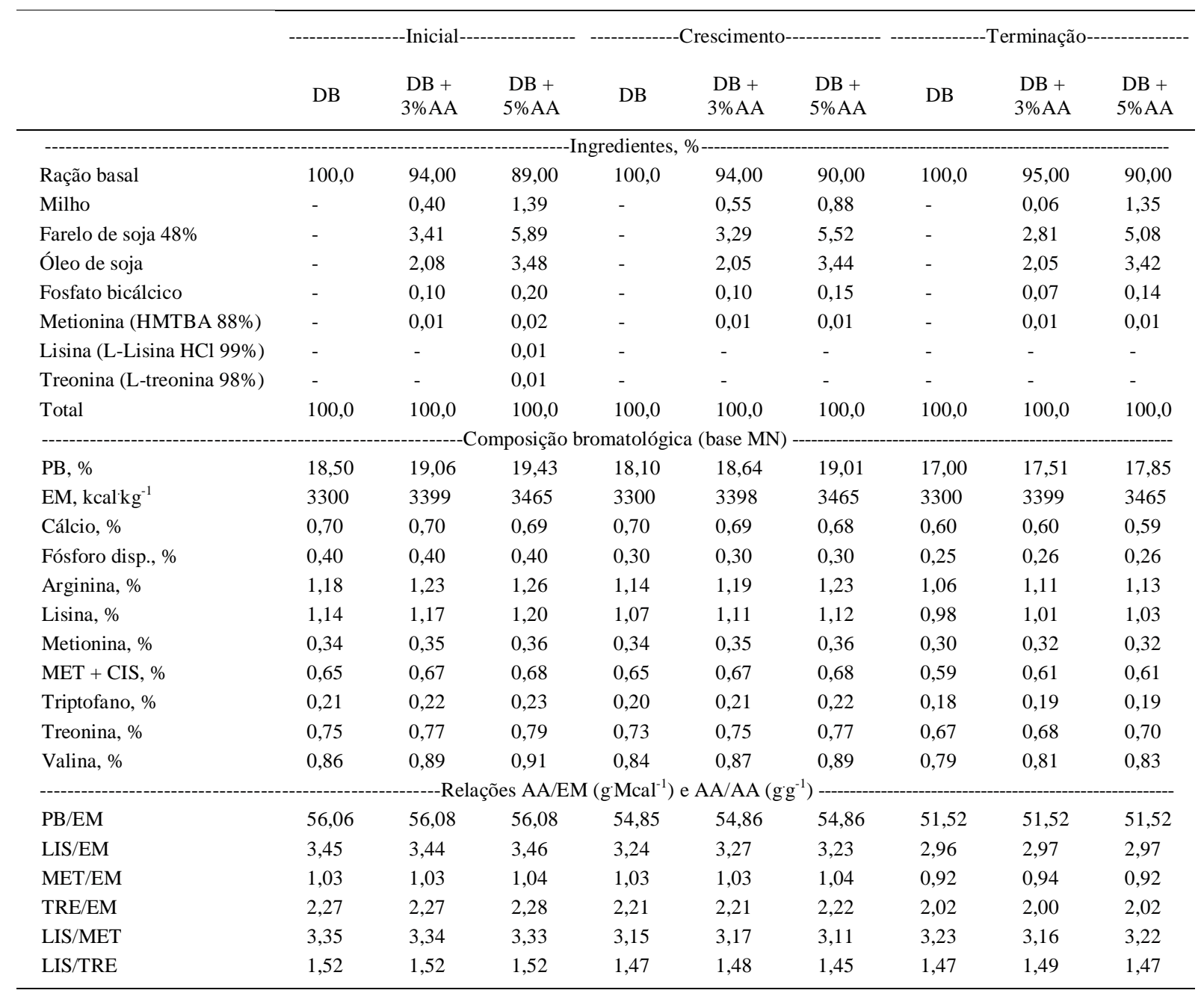

DB: Dieta basal; AA: Aminoácidos; PB: Proteína bruta; EM: Energia metabolizável; MET: Metionina; CIS: Cistina; LIS: Lisina; TRE: Treonina.

O peso de abate, peso e rendimento de carcaça fria foram influenciados $(\mathrm{P}<0,05)$ pela categoria sexual (Tabela 2 e 3 ). $\mathrm{O}$ rendimento de carcaça fria foi melhor $(\mathrm{P}<0,05)$ nos suínos machos castrados em relação aos machos imunocastrados, independente da suplementação.

Após a imunocastração, reduz a agressão e o comportamento sexual dos suínos, o que favorece o crescimento, a deposição de carne e melhora a deposição de gordura intramuscular dos suínos machos imunocastrados em relação aos machos inteiros (OLIVER et al., 2003). Porém, o peso adicional do trato reprodutivo é responsável pelo baixo rendimento de carcaça fria dos suínos machos imunocastrados (DUNSHEA et al., 2001).
Suínos machos imunocastrados suplementados com $5 \%$ a mais de aminoácidos e energia apresentaram costela $19 \%$ mais $(\mathrm{P}<0,05)$ pesada e melhor $(\mathrm{P}<0,05)$ rendimento em relação aos machos castrados alimentados com a dieta basal (Tabela 2 e 3). Já os suínos machos castrados apresentaram peso de carré $13 \%$ superior $(\mathrm{P}<0,05)$ e melhor rendimento em relação aos imunocastrados, ambos alimentados com a dieta basal. Os suínos machos imunocastrados apresentaram melhor $(\mathrm{P}<0,05)$ peso e rendimento de pernil e pior $(\mathrm{P}<0,05)$ peso e rendimento de carré.

Vários fatores influenciam na taxa de crescimento dos suínos, tais como os níveis de proteína, aminoácidos e ingestão de energia para cada 
Tabela 2 - Peso de carcaça e cortes (kg) de suínos machos castrados e imunocastrados alimentados com diferentes níveis de aminoácidos e energia com ou sem ractopamina.

\begin{tabular}{|c|c|c|c|c|c|c|c|c|c|c|c|c|}
\hline Tratamentos & $\begin{array}{l}\text { Peso } \\
\text { Abate }\end{array}$ & $\begin{array}{l}\text { Carcaça } \\
\text { quente }^{1}\end{array}$ & $\begin{array}{c}\text { Carcaça } \\
\text { fria }^{1}\end{array}$ & Cabeça & Pernil & Paleta & Barriga & Costela & Carré & Lombo & Papada & Filé \\
\hline $\mathrm{DB}-\mathrm{MC}$ & $125,9^{b}$ & 100,2 & $96,3^{\mathrm{a}}$ & 4,59 & 13,66 & 15,60 & 9,16 & $1,74^{\mathrm{b}}$ & $6,98^{\mathrm{a}}$ & 3,14 & 2,11 & 0,87 \\
\hline DB - MI & $130,1^{\mathrm{a}}$ & 99,3 & $95,0^{b}$ & 4,82 & 14,59 & 15,14 & 8,52 & $1,95^{\mathrm{ab}}$ & $6,14^{\mathrm{b}}$ & 2,97 & 1,78 & 0,80 \\
\hline $\mathrm{DB}+3 \% \mathrm{AA}-\mathrm{MI}$ & $130,9^{\mathrm{a}}$ & 101,6 & $95,8^{\mathrm{b}}$ & 4,86 & 14,43 & 15,04 & 8,87 & $1,92^{\mathrm{ab}}$ & $6,59^{\mathrm{ab}}$ & 3,02 & 1,49 & 0,86 \\
\hline $\mathrm{DB}+5 \% \mathrm{AA}-\mathrm{MI}$ & $130,8^{\mathrm{a}}$ & 101,5 & $95,7^{\mathrm{b}}$ & 4,86 & 14,13 & 15,08 & 9,42 & $2,08^{\mathrm{a}}$ & $6,34^{\mathrm{ab}}$ & 2,88 & 1,68 & 0,85 \\
\hline epr ${ }^{2}$ & 5,95 & 2,77 & 2,04 & 0,25 & 0,66 & 1,30 & 0,68 & 0,19 & 0,47 & 0,28 & 0,40 & 0,08 \\
\hline Tratamento & 0,02 & 0,36 & 0,03 & 0,28 & 0,10 & 0,89 & 0,08 & 0,05 & 0,03 & 0,45 & 0,12 & 0,33 \\
\hline Sem & 119,8 & 94,0 & 91,5 & 4,66 & $\begin{array}{c}\text { Ractopa } \\
13,70\end{array}$ & $\begin{array}{c}\text { nina - M } \\
15,90\end{array}$ & 8,56 & 1,68 & 6,95 & 2,99 & 1,87 & --- \\
\hline Com & 128,0 & 101,6 & 96,7 & 4,58 & 13,48 & 14,42 & 9,23 & 1,88 & 7,31 & 3,12 & 1,90 & 0,85 \\
\hline & & & & & Ractopa & hina - M & & & & & & ---- \\
\hline Sem & 126,0 & 96,9 & 92,3 & 4,85 & 14,05 & 14,51 & 8,83 & 1,88 & 6,18 & 2,87 & 1,62 & 0,81 \\
\hline Com & 132,1 & 103,1 & 97,0 & 4,63 & 14,12 & 15,21 & 8,95 & 2,00 & 6,07 & 3,03 & 1,87 & 0,86 \\
\hline epr ${ }^{2}$ & 5,04 & 1,83 & 1,70 & 0,16 & 0,31 & 0,97 & 0,60 & 0,20 & 0,33 & 0,29 & 0,23 & 0,06 \\
\hline & & & & & --Proba & ilidades & 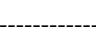 & & & & & --- \\
\hline Ractopamina (R) & 0,00 & 0,03 & 0,31 & 0,25 & 0,76 & 0,61 & 0,41 & 0,33 & 0,65 & 0,54 & 0,44 & 0,68 \\
\hline Categoria (C) & 0,01 & 0,75 & 0,01 & 0,31 & 0,04 & 0,66 & 0,99 & 0,27 & 0,00 & 0,62 & 0,40 & 0,69 \\
\hline $\mathrm{R} * \mathrm{C}$ & 0,94 & 0,93 & 0,11 & 0,38 & 0,36 & 0,06 & 0,39 & 0,71 & 0,18 & 0,94 & 0,35 & 0,36 \\
\hline
\end{tabular}

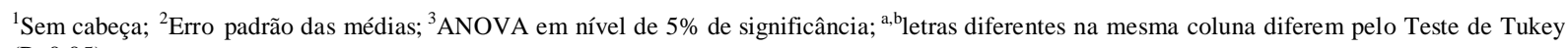
$(\mathrm{P}<0,05)$.

DB: Dieta basal; MC: Machos castrados; MI: Machos imunocastrados; AA: Aminoácidos.

categoria sexual (VAN MILGEN et al., 2000). A lisina éo aminoácido que mais influencia na deposição proteica pelos suínos em crescimento, devido a sua constância na proteína corporal (KIM et al., 2009). A imunocastração pode não afetar peso e rendimento dos principais cortes (FUCHS et al., 2009), o que pode ser explicado pelo crescimento compensatório dos suínos machos imunocastrados em comparação com castrados, no final da terminação (PAULY et al., 2009).

Um dos efeitos mais conhecidos da ractopamina em suínos é o incremento da massa muscular com aumento da quantidade de carne magra na carcaça (SEE et al., 2004). De maneira geral, constatase que a ractopamina propicia respostas semelhantes em termos de crescimento e deposição de tecido muscular na carcaça, tanto em machos castrados como em fêmeas (UTTARO et al., 1993), mas não apresenta o mesmo comportamento nos machos inteiros (DUNSHEA et al., 1993). Esses resultados podem indicar que, assim como os suínos machos inteiros, os imunocastrados podem não responder à inclusão de ractopamina na dieta.

A categoria sexual influenciou $(\mathrm{P}<0,05)$ o $\mathrm{pH}$ as $24 \mathrm{~h}$ e não houve diferenças $(\mathrm{P}>0,05)$ para perda de peso na carne de suínos machos castrados e imunocastrados (Tabela 4). Devido ao comportamento dos suínos machos imunocastrados, maior nível de agressividade e atividade física, é indicado na literatura que as reservas de glicogênio muscular podem reduzir, afetando o $\mathrm{pH}$ e qualidade da carne desse tipo de animal (CRONIN et al., 2003). Porém, no presente estudo, só foi observada essa influência às 24h pós-abate.

Suínos machos imunocastrados suplementados com $5 \%$ de aminoácidos e energia apresentaram valor superior $(P<0,05)$ da coloração $b^{*}$ (amarelo-azul) na carne aos $45 \mathrm{~min}$ e às $24 \mathrm{~h}$ pós-abate, em relação aos machos castrados alimentados com dieta basal, e às $24 \mathrm{~h}$ pós-abate também em relação aos machos imunocastrados alimentados com a dieta basal (Tabela 4). A categoria sexual influenciou na coloração $a^{*}$ (vermelho-verde) aos $45 \mathrm{~min}$ e na coloração b* (amarelo-azul) às 24 horas. A ractopamina não influenciou $(\mathrm{P}>0,05)$ na qualidade de carne de suínos machos castrados e imunocastrados.

As alterações no teor de amarelo podem ser um indicativo de mudanças na composição de ácidos graxos da gordura intramuscular. $\mathrm{O}$ tecido adiposo de suínos machos inteiros tem um menor teor de lipídeos 
Tabela 3 - Rendimento de carcaça e cortes (\%) de suínos machos castrados e imunocastrados alimentados com diferentes níveis de aminoácidos e energia com ou sem ractopamina.

\begin{tabular}{|c|c|c|c|c|c|c|c|c|c|c|c|}
\hline Tratamentos & $\begin{array}{l}\text { Carcaça } \\
\text { quente }^{1}\end{array}$ & $\begin{array}{c}\text { Carcaça } \\
\text { fria }^{1}\end{array}$ & Cabeça & Pernil & Paleta & Barriga & Costela & Carré & Lombo & Papada & Filé \\
\hline DB - MC & 79,24 & $76,28^{\mathrm{a}}$ & 3,56 & 10,57 & 12,08 & 7,10 & $1,34^{\mathrm{b}}$ & $5,44^{\mathrm{a}}$ & 2,45 & 1,65 & 0,68 \\
\hline DB - MI & 76,93 & $73,46^{\mathrm{b}}$ & 3,74 & 11,31 & 11,71 & 6,60 & $1,51^{\mathrm{ab}}$ & $4,76^{\mathrm{b}}$ & 2,30 & 1,38 & 0,62 \\
\hline $\mathrm{DB}+3 \% \mathrm{AA}-\mathrm{MI}$ & 77,97 & $73,44^{\mathrm{b}}$ & 3,76 & 11,17 & 11,64 & 6,88 & $1,49^{\mathrm{ab}}$ & $5,10^{\mathrm{ab}}$ & 2,34 & 1,16 & 0,67 \\
\hline $\mathrm{DB}+5 \% \mathrm{AA}-\mathrm{MI}$ & 77,85 & $73,36^{\mathrm{b}}$ & 3,77 & 10,96 & 11,67 & 7,30 & $1,61^{\mathrm{a}}$ & $4,91^{\mathrm{ab}}$ & 2,23 & 1,30 & 0,66 \\
\hline $\mathrm{epr}^{2}$ & 2,18 & 1,62 & 0,19 & 0,51 & 1,02 & 0,53 & 0,15 & 0,36 & 0,22 & 0,31 & 0,06 \\
\hline \multicolumn{12}{|c|}{-Probabilidade ${ }^{3}$} \\
\hline Tratamento & 0,34 & 0,02 & 0,26 & 0,10 & 0,89 & 0,08 & 0,04 & 0,02 & 0,39 & 0,11 & 0,28 \\
\hline Sem & 78,36 & 76,36 & 3,67 & 10,78 & 12,52 & 6,75 & 1,32 & 5,49 & 2,38 & 1,48 & 0,68 \\
\hline Com & 79,33 & 75,44 & 3,61 & 10,61 & 11,36 & 7,26 & 1,48 & 5,75 & 2,45 & 1,50 & 0,67 \\
\hline \multicolumn{12}{|c|}{------Ractopamina - MI----- } \\
\hline Sem & 76,86 & 73,18 & 3,82 & 11,05 & 11,40 & 6,97 & 1,49 & 4,87 & 2,26 & 1,28 & 0,64 \\
\hline Com & 78,11 & 73,39 & 3,65 & 11,12 & 12,00 & 7,04 & 1,56 & 4,79 & 2,38 & 1,49 & 0,68 \\
\hline $\mathrm{epr}^{2}$ & 1,49 & 1,42 & 0,12 & 0,24 & 0,84 & 0,48 & 0,16 & 0,27 & 0,24 & 0,18 & 0,05 \\
\hline \multicolumn{12}{|c|}{-Probabilidades ${ }^{3}$} \\
\hline Ractopamina (R) & 0,03 & 0,37 & 0,25 & 0,78 & 0,67 & 0,44 & 0,37 & 0,67 & 0,60 & 0,41 & 0,67 \\
\hline Categoria (C) & 0,81 & 0,01 & 0,29 & 0,04 & 0,68 & 1,00 & 0,28 & 0,00 & 0,59 & 0,41 & 0,72 \\
\hline $\mathrm{R} * \mathrm{C}$ & 0,95 & 0,09 & 0,36 & 0,36 & 0,06 & 0,38 & 0,64 & 0,24 & 0,84 & 0,30 & 0,32 \\
\hline
\end{tabular}

${ }^{1}$ Sem cabeça; ${ }^{2}$ Erro padrão das médias; ${ }^{3}$ ANOVA em nível de 5\% de significância; ${ }^{\text {a,b }}$ letras diferentes na mesma coluna diferem pelo Teste de Tukey $(\mathrm{P}<0,05)$.

DB: Dieta basal; MC: Machos castrados; MI: Machos imunocastrados; AA: Aminoácidos.

e o grau de insaturação é maior do que nos machos castrados (PAULY et al., 2008). A composição de ácidos graxos de suínos machos imunocastrados deve ser intermediária entre machos inteiros e castrados (GISPERT et al., 2010). Os resultados de qualidade de carne mostram a influência dos tratamentos na coloração a* (vermelho-verde) e b* (amarelo-azul), porém essa diferença não é detectada pelo olho humano e os valores são considerados bons.

A ação da ractopamina sobre as características que determinam a qualidade da carcaça depende da linhagem de suínos usada, da quantidade desse aditivo e do tempo de fornecimento (BRIDI et al., 2006). O uso de ractopamina em dietas para suínos não afeta de forma consistente as medidas de qualidade da carne, como perda de peso por gotejamento e $\mathrm{pH}$ final (CARR et al., 2005; BRIDI et al., 2006). No entanto, há relatos de alterações sobre os teores de vermelho e amarelo (UTTARO et al., 1993; CARR et al., 2005). O uso de ractopamina na alimentação de suínos não afeta a qualidade da carne.

A proposta da imunocastração é manter as vantagens produtivas dos suínos machos inteiros durante boa parte da fase de crescimento e terminação.
As respostas encontradas neste trabalho para características de carcaça e qualidade da carne foram pouco afetadas pela imunocastração. Houve influência da categoria sexual na carcaça fria, pernil, carré, $\mathrm{pH}$ e coloração a* (vermelho-verde) e b* (amarelo-azul). Já a adição de ractopamina melhorou o peso de abate e de carcaça quente e a suplementação com $5 \%$ a mais de aminoácidos e energia alterou o rendimento de costela e o valor da coloração b* (amarelo-azul).

\section{CONCLUSÃO}

Os suínos machos imunocastrados apresentam peso de abate 3,3\% superior e peso de carcaça fria 1,4\% inferior em relação aos machos castrados. A suplementação com $5 \%$ a mais de aminoácidos e energia aumenta o peso e rendimento de costela e altera o valor da coloração b* (amareloazul) na carne dos suínos machos imunocastrados em relação aos castrados. A ractopamina melhora o peso de abate e de carcaça quente. A categoria sexual influencia no peso e rendimento de carcaça fria, pernil e carré, coloração a* (vermelho-verde) e b* (amareloazul) e pH da carne.

Ciência Rural, v.42, n.11, nov, 2012. 
Tabela 4 - pH, cor e perda de peso (\%) da carne de suínos machos castrados e imunocastrados alimentados com diferentes níveis de aminoácidos e energia com ou sem ractopamina.

\begin{tabular}{|c|c|c|c|c|c|c|c|c|c|c|c|}
\hline TRAT & $\mathrm{pH} 45 \mathrm{~min}$ & $\mathrm{~L}^{*}$ & $a^{*}$ & $b^{*}$ & $\mathrm{pH} 24 \mathrm{~h}$ & Perda peso & $\mathrm{L}^{*}$ & $a^{*}$ & $b^{*}$ & $\mathrm{pH} 48 \mathrm{~h}$ & Perda peso \\
\hline DB - MC & 6,17 & 35,65 & 10,41 & $-6,26^{\mathrm{b}}$ & 5,71 & $-2,08$ & 42,00 & 12,26 & $-5,71^{b}$ & 5,32 & $-2,09$ \\
\hline DB - MI & 6,09 & 35,13 & 12,18 & $-6,18^{\mathrm{ab}}$ & 5,77 & $-1,87$ & 41,82 & 12,24 & $-5,50^{\mathrm{b}}$ & 5,43 & $-1,77$ \\
\hline $\mathrm{DB}+3 \% \mathrm{AA}-\mathrm{MI}$ & 6,44 & 35,11 & 10,99 & $-5,95^{a b}$ & 5,78 & $-2,20$ & 42,72 & 12,07 & $-5,28^{a b}$ & 5,17 & $-1,66$ \\
\hline $\mathrm{DB}+5 \% \mathrm{AA}-\mathrm{MI}$ & 6,21 & 36,12 & 12,23 & $-5,58^{\mathrm{a}}$ & 5,54 & $-2,56$ & 43,38 & 12,61 & $-4,74^{\mathrm{a}}$ & 5,31 & $-1,74$ \\
\hline epr ${ }^{1}$ & 0,31 & 1,35 & 2,42 & 0,43 & 0,30 & 0,53 & 2,00 & 0,99 & 0,51 & 0,32 & 0,71 \\
\hline & \multicolumn{11}{|c|}{-Probabilidade ${ }^{2}$} \\
\hline Tratamento & 0,18 & 0,42 & 0,45 & 0,04 & 0,39 & 0,11 & 0,46 & 0,75 & 0,02 & 0,50 & 0,78 \\
\hline Sem & 6,23 & 36,23 & 9,94 & $-6,07$ & $\begin{array}{c}\text { Ractopam } \\
5,46\end{array}$ & $\begin{array}{c}\text { na - MC--- } \\
-2,27\end{array}$ & 41,30 & 12,49 & $-5,89$ & 5,36 & $-1,89$ \\
\hline Com & 6,07 & 35,68 & 10,61 & $-6,38$ & 5,62 & $-1,79$ & 42,74 & 11,85 & $-5,66$ & 5,27 & $-2,36$ \\
\hline \multicolumn{12}{|c|}{--Ractopamina - MI----- } \\
\hline Sem & 6,25 & 35,36 & 11,09 & $-5,95$ & 5,66 & $-2,17$ & 41,86 & 12,12 & $-5,41$ & 5,38 & $-1,73$ \\
\hline Com & 6,27 & 35,09 & 12,92 & $-5,90$ & 6,00 & $-2,34$ & 43,01 & 12,62 & $-4,97$ & 5,24 & $-1,53$ \\
\hline epr $^{1}$ & 0,21 & 0,88 & 0,84 & 0,46 & 0,19 & 0,43 & 1,04 & 0,67 & 0,23 & 0,33 & 0,73 \\
\hline \multicolumn{12}{|c|}{-Probabilidades ${ }^{2}$} \\
\hline Ractopamina (R) & 0,67 & 0,55 & 0,08 & 0,73 & 0,11 & 0,65 & 0,13 & 0,89 & 0,09 & 0,66 & 0,81 \\
\hline Categoria (C) & 0,46 & 0,25 & 0,01 & 0,36 & 0,05 & 0,46 & 0,58 & 0,67 & 0,00 & 0,99 & 0,35 \\
\hline $\mathrm{R} * \mathrm{C}$ & 0,38 & 0,76 & 0,20 & 0,45 & 0,35 & 0,16 & 0,79 & 0,12 & 0,38 & 0,86 & 0,37 \\
\hline
\end{tabular}

${ }^{1}$ Erro padrão das médias; ${ }^{2}$ ANOVA em nível de 5\% de significância; a,bletras diferentes na mesma coluna diferem pelo Teste de Tukey $(\mathrm{P}<0,05)$.

DB: Dieta basal; MC: Machos castrados; MI: Machos imunocastrados; AA: Aminoácidos; L*: Luminosidade; a*: componente (vermelhoverde); b*: componente (amarelo-azul).

\section{AGRADECIMENTOS}

Ao Conselho Nacional para o Desenvolvimento Científico e Tecnológico (CNPq), à Comissão de Aperfeiçoamento de Pessoal de Nível Superior (Capes) e às empresas Adisseo e Pfizer, pela infraestrutura para realização do trabalho e financiamento parcial do projeto.

\section{COMITÊ DE ÉTICA E BIOSSEGURANÇA}

Protocolo nํo 003/2011.

\section{REFERÊNCIAS}

ARMSTRONG, T.A. et al. The effect of dietary ractopamine concentration and duration of feeding on growth performance, carcass characteristics, and meat quality of finishing pigs. Journal of Animal Science, v.82, n.11, p.3245-3253, 2004. Disponível em: <http://jas.fass.org/cgi/content/abstract/82/11/ 3245>. Acesso em: 02 out. 2011.

BRIDI, A.M. et al. Efeito do genótipo halotano, da ractopamina e do sexo do animal na qualidade da carne suína. Revista Brasileira de Zootecnia, v.35, p.2027-2033, 2006. Disponível em: <http:/ /www.scielo.br/scielo.php?script=sci_arttext\&pid=S151635982006000700021\&nrm=iso>. Acesso em: 17 set. 2011.

CARR, S.N. et al. The effects of ractopamine hydrochloride on lean carcass yields and pork quality characteristics. Journal of
Animal Science, v.83, n.12, p.2886-2893, 2005. Disponível em: <http://jas.fass.org/content/83/12/2886.abstract $>$. Acesso em: 18 set. 2011.

CRONIN, G. et al. The effects of immuno- and surgical-castration on the behaviour and consequently growth of group-housed, male finisher pigs. Applied Animal Behaviour Science, v.81, p.111126, 2003. Disponível em: <http://www.journals.elsevierhealth.com/ periodicals/applan/article/S0168-1591(02)00256-3/abstract>. Acesso em: 01 out. 2011. doi: 10.1016/S0168-1591(02)00256-3.

DUNSHEA, F.R. et al. Vaccination of boars with a GnRH vaccine (Improvac) eliminates boar taint and increases growth performance. Journal of Animal Science, v.79, n.10, p.25242535, 2001. Disponível em: <http://jas.fass.org/cgi/content/ abstract/79/10/2524>. Acesso em: 15 set. 2011.

DUNSHEA, F.R. et al. Interrelationships between sex and ractopamine on protein and lipid deposition in rapidly growing pigs. Journal of Animal Science, v.71, n.11, p.2919-2930, 1993. Disponível em: <http://jas.fass.org/cgi/content/abstract/ 71/11/2919>. Acesso em: 15 set. 2011.

FUCHS, T. et al. A comparison of the carcase characteristics of pigs immunized with a 'gonadotrophin-releasing factor (GnRF)' vaccine against boar taint with physically castrated pigs. Meat Science, v.83, n.4, p.702-705, 2009. Disponível em: <http:/ /www.sciencedirect.com/science/article/B6T9G-4WY6K31-6/2/ 81eaf51ae1d4f4466dd963f044e66950>. Acesso em: 10 ago. 2011. doi: 10.1016/j.meatsci.2009.08.007. 
GISPERT, M. et al. Carcass and meat quality characteristics of immunocastrated male, surgically castrated male, entire male and female pigs. Meat Science, v.85, n.4, p.664-670, 2010. Disponível em: <http://www.sciencedirect.com/science/article/ pii/S0309174010000938>. Acesso em: 10 ago. 2011. doi: 10.1016/j.meatsci.2010.03.021.

KIM, B.G. et al. Amino acid digestibility and energy concentration in a novel source of high-protein distillers dried grains and their effects on growth performance of pigs. Journal of Animal Science, v.87, n.12, p.4013-4021, 2009. Disponível em: <http:/ /jas.fass.org/cgi/content/abstract/87/12/4013>. Acesso em: 04 out. 2011. doi: 10.2527/jas.2009-2060.

MINITAB. User's guide: Meet Minitab 15, Stat College, PA, 2007. 142p.

OLIVER, W.T. et al. A gonadotropin-releasing factor vaccine (Improvac) and porcine somatotropin have synergistic and additive effects on growth performance in group-housed boars and gilts. Journal of Animal Science, v.81, n.8, p.19591966, 2003. Disponível em: <http://jas.fass.org/cgi/content/ abstract/81/8/1959>. Acesso em: 20 ago. 2011.

PAULY, C. et al. Performances, meat quality and boar taint of castrates and entire male pigs fed a standard and a raw potato starch-enriched diet. Animal, v.2, p.1707-1715, 2008. Disponível em: <http://journals.cambridge.org/action/ displayAbstract ?fromPage $=$ online $\&$ aid $=2468608>$. Acesso em: 28 ago. 2011
PAULY, C. et al. Growth performance, carcass characteristics and meat quality of group-penned surgically castrated, immunocastrated $\left(\operatorname{Improvac}^{\mathrm{R}}\right)$ and entire male pigs and individually penned entire male pigs. Animal, v.3, p.10571066, 2009. Disponível em: <http://journals.cambridge.org/ action/displayAbstract fromPage $=$ online $\&$ aid $=5749664>$. Acesso em: 15 set. 2011. doi: 10.1017/S1751731109004418.

SEE, M.T. et al. Effect of a ractopamine feeding program on growth performance and carcass composition in finishing pigs. Journal of Animal Science, v.82, n.8, p.2474-2480, 2004. Disponível em: <http://jas.fass.org/content/82/8/2474.abstract>. Acesso em: 10 out. 2011.

UTTARO, B.E. et al. Effect of ractopamine and sex on growth, carcass characteristics, processing yield, and meat quality characteristics of crossbred swine. Journal of Animal Science, v.71, n.9, p.2439-2449, 1993. Disponível em: <http://jas.fass.org/ cgi/content/abstract/71/9/2439>. Acesso em: 10 out. 2011.

VAN MILGEN, J. et al. Modeling the relation between energy intake and protein and lipid deposition in growing pigs. Journal of Animal Science, v.71, p.119-130, 2000. Disponível em: <http://www.bsas.org.uk/Publications/Animal_Science/2000/ Volume_71_Part_1/119/>. Acesso em: 14 out. 2011.

ZAMARATSKAIA, G. et al. Effect of a gonadotropin-releasing hormone vaccine $\left(\right.$ Improvac $^{\mathrm{TM}}$ ) on steroid hormones, boar taint compounds and performance in entire male pigs. Reproduction in Domestic Animals, v.43, n.3, p.351-359, 2008. Disponível em: <http://dx.doi.org/10.1111/j.1439-0531.2007.00914.x> Acesso em: 16 set. 2011. doi: 10.1111/j.1439-0531.2007.00914.x. 